\title{
Visual and Verbal Communication in the Music Video Clip Entitled "Millionaires"
}

\author{
Lau Yoseph Anggara Putra Meta ${ }^{1}$, Sang Ayu Isnu Maharani², I Made Rajeg ${ }^{3}$ \\ ${ }^{123}$ English Department - Faculty of Arts - Udayana University \\ laujoseph29@gmail.com¹ isnu.maharani@yahoo.com² imaderajeg@gmail.com ${ }^{3}$ \\ Denpasar,Bali,Indonesia
}

\begin{abstract}
This study is aimed at analyzing the elements of visual and verbal communication and the messages of the song lyrics of millionaires. The data of this study collected intensively through watching the music video clip and note-taking. In analyzing the data this study uses the main theory of principle visual communication elements by Dyer (1993), theory of sign by Goodwin (1992), and theory of meaning proposed by Leech (1974). The findings showed that the use of visuals was found 13 elements are appearance, manner, activity, props, and setting, visual or images. As for verbal communication elements, the finding showed 4 meanings representation: conceptual meaning, connotative meaning, affective meaning, and thematic meaning. Furthermore, there is a correlation between visual signs and verbal representation in the video clip as well as the meaning of the song lyrics.
\end{abstract}

Keywords: visual, verbal, communications, elements, meaning.

\section{INTRODUCTION}

Verbal sign, according to Chandler (2001: 27 ) is something that deals with text and words. According to Halliday (1985: 43), a text is a language in operation and a product of its environment and functions in that environment. Chandler (2001: 10) defined a visual sign as pictures, which presented the kind of the products, logo of a company, etc.

A music video is a short film integrating a song and imagery, produced for promotional or artistic purposes. Modern music videos are primarily made and used as a marketing device intended to promote the sale of music recordings. Although the origins of music videos date back much further, they came into prominence in the 1980s, when MTV based their format on the medium. Prior to the 1980s, this work was described by various terms including "illustrated song", "filmed insert", "promotional (promo) film", "promotional clip", "promotional video", "song video", "song clip" or "film clip". Music videos use a wide range of styles of contemporary video-making techniques, including animation, live-action filming, documentaries, and non-narrative approaches such as abstract film. Some music videos blend different styles, such as animation, music, and live-action. Many music videos interpret images and scenes from the song's lyrics, while others take a more thematic approach. Other music videos may be without a set concept, being merely a filmed version of the song's live performance.

The paper entitled analysis of Verbal and Visual Aspects in Taylor Swift's Music Video Out of the Woods (Ayu, Putu 2017). The purpose of this study is divided into two types. The general objective is to apply and develop 
linguistic theories and other theories related to this study. Specific objectives focus more on the relationship between music videos and Taylor Swift's personal experience. The data analysis method used is the descriptive method. Data analysis techniques by applying Semantic theory from Geoffrey Leech (1974) to analyze verbal aspects in the form of song lyrics and writing in the video. The Semiotic Theory from Ferdinand de Saussure (1916) and the theory of color meaning from Herman Cerrato (2012) are used to analyze visual aspects in the form of screenshots. The results of this studio show that verbal aspects in this music video include six types of meaning (conceptual, affective, reflection, collocative, connotative, and thematic). Visual aspects are added by markers and marked with six colors: white, black, blue, green, yellow, and orange.

The Undergraduate thesis with the title Visual and Verbal Communication in Michael Jackson's Video Clip Entitled "Black or White" (Ayu, 2016). This thesis aims to analyze the usefulness of visual and verbal communication and also to find the relationship between visual and verbal elements with the meaning of the song in Michael Jackson's video clip. In collecting data, this thesis uses qualitative methods. In collecting data three steps are used, namely first, selecting the data properly, secondly finding the sign and classifying the data based on its type, and finally, the message conveyed in the data found. In analyzing the data used visual communication theory by Dyer (1993), verbal representation theory by Dyer in his book entitled Advertising as Communication, and the theory of meaning by Leech (1974). The results of the analysis show the usefulness of verbal and visual communication elements in music video clips depends on the content of the music video clip itself. Video clips that sound hidden stories or messages use more visual and verbal communication than video clips that do not have moral messages.

The paper entitled "Verbal and Visual Communication in The Hunger Games Films" seeks to reveal and discover the form of sentences from the verbal speech of characters, visual signs of scenes between characters, and the relationship between these communications. In that study, the film The Hunger Games was used as a data source. The method used to analyze films is qualitative. The main theory used was proposed by Dyer (1986) with Verbal theory and Visual Communication and assisted by using theory from Timothy Shopen (2007) which explains the types of sentences in the form of verbal speech. The results of this study indicate the difference between two different social classes; they are upper and lower class. How upper-class characters speak, act and look, tends to be more polite, prestigious, classy, colorful, and more educated than lower-class characters. It shows the relationship between visual and verbal communication itself (Fridayanti, 2018).

The undergraduate paper is entitled "Verbal and Visual Signs of Advertisement in National Geographic Traveller Magazine". The aims are to describe the meaning and function of verbal and visual signs and how their interrelations are. The source of the National Geographic Traveller Magazine from which the three advertisements are selected, these selections are due to advertisements presents a good combination of colors, pictures, and word choices than another advertisement which also consist of verbal and visual signs. The research is done through library research with documentation method and observation technique was applied to collect the data, the qualitative method was used to analyze the data based on the theory of meaning and function by Leech, theory of signs by Chandler, and use of 
color by Cerrato. The result of the analysis shows that the advertiser tends to use conceptual meaning and informational function to deliver or give information to the readers about the product itself (Prawiranatha, 2018).

This research entitled "The Analysis of Verbals and Visual Signs of Adidas Advertisement" (Adi, I Putu. 2016), explains verbal and visual signs in advertisements. This study also analyzes verbal and visual signs that support Adidas advertising and the function and meaning of verbal and visual signs. The method used in data collection is the purposive sampling method and the data collected has been analyzed qualitatively based on semiotic theory. There are four theories used in this study. These theories are visual and verbal sign theory by Dyer (1993), theory of meaning and function by Leech (1974), sign theory outlined by Chandler (2001), and color theory by Chapman (2010). Concerning the results of this study, the meanings and functions of the signs in advertisements can be detected from ad makers who inform information about Adidas, to sell or promote their products and also to create brand images and consumers can understand the meaning of Adidas advertisements.

This study discusses "Verbal and Visual Signs of NIKE advertisements: A Semiotic Analysis", which describes verbal and visual signs in advertisements. This study also analyzes the verbal and visual signs that support NIKE advertising and the function and meaning of the verbal and visual signs that are in advertisements. There are four theories used in this study, namely the visual and verbal sign theory proposed by Dyer (1993), the theory of meaning and function put forward by Leech (1977), the sign theory explained by Chandler (2001), and the color theory put forward by Chapman (2010). The result of this study expressive functions is used to express the feelings and attitudes of its originators. Conceptual meaning is also used in providing information from messages so that readers capture messages from advertisements and also the dominant conceptual meaning in the use of language information (Bagus, I Gusti. 2015).

This research is entitled "Analysis of Product Advertisements on magazines with Verbal and Visual signs". The purpose of this study was to analyze the verbal and visual signs of print advertisements and to find out the messages conveyed in each printed advertising product. More specifically, it is intended to analyze the meaning and function of verbal and visual signs to help the reader understand the message of the printed product advertisement. This research also uses the theory of meaning put forward by Leech (1974) in his book entitled "Semantics: Study of Meaning "Button. $\mathrm{He}$ stated that in general advertising (print advertising) consists of the following standard components such as title, illustration, body copy, signature line (logo), standing details, and meaning classified into seven types and five language functions. The results of the analysis show that verbal and visual signs are correlated and are very important for making good advertisements. This analysis concludes that each magazine has a different way of delivering its advertisements, both in terms of structure and components (Asti, Ni Putu. 2014).

This paper is entitled 'Connotative Meaning of Verbal and Visual Signs in Printed Perfume Advertisements' (Suarmita, 2016). The purpose of this study is to look for connotative meanings of verbal signs and visual signs in perfume print advertisements and analyze the relationship between verbal signs and visual signs in creating connotative meanings. The qualitative method is used as a research method in this study. There are two main theories used to analyze data. The first is 'dyadic theory' from 
Saussure (1983) to analyze connotative meanings. The second is the theory from Berger (1984) for analyzing visual signs. Meanwhile, the theory proposed by Leech (1972) is to analyze the verbal sign on the structure of advertising. And the theory proposed by Dyer (1982) is used to analyze the connotative meaning in advertising. Based on the analysis, the connotative meaning of verbal signs in advertisements usually occurs in simple and short sentences to attract the attention of the audience and advertisers also choose simple sentences that are easy to remember. The connotative meaning may be difficult to understand, but it can make advertising more interesting. Visual signs that contain connotative meaning can be found in terms of size, spatiality, contrast, shape, and color.

This study is entitled "Verbal and Visual messages in English printed car advertisements". The discussion in this study aims to analyze verbal and visual messages in each car advertisement and find out the message delivered in each car ad. More specifically, it is intended to analyze the meaning and the function of verbal and visual signs to help readers understand the message of printed car advertisements. The method used in this study is the method of documentation and theory of meaning by Leech. Through the analysis, it shows that verbal and visual messages have a relationship to make good advertisements, based on explanations, we can get some points about advertisements such as advertisements must have verbal and visual signs to attract the attention of readers, a good ad must be chosen in using words for information conveyed and messages to readers so they can become understood (Arriawan, 2014).

This Thesis is entitled Verbal and Visual Sign in Doushite Kimi Wo Suki Ni Natte
Shimattan Darou and Stand By U Music Video (Sriumiyanti, 2014). The collection data method and technique used in this study is the seeing, listening method, and note taking technique. The analysis method used in this study is a qualitative analysis with selection technique, and presentation of data analysis results used informal methods with inductive technique. This research is aimed at describing the element of visual communication and the relation between verbal and visual signs in Music videos. Those data were analyzed based on the theory of Gillian Dyer about element visual communication, theory of Semiotics proposed by Ogden \& Richard, and theory of meaning by Leech. The result of the analysis found that eleven elements of visual communications in the Doushite Kimi Wo Suki Ni Natte shimattan Darou and Stand By $U$ Music Video. Relation of verbal and visual signs in that video tell about regret and broken heart of man.

This paper is entitled "Analysis of Verbal and Visual Signs in Women's Cosmetic Advertisements" which is intended to support the absence of verbal and visual signs needed in advertisements on women's cosmetics. The method used in this study is a qualitative method and the steps begin by collecting data in a magazine. This paper uses two theories, the first theory is sign theory to analyze the meaning contained in verbal and visual signs put forward by Saussure (Chandler 1997). The second theory is the theory of advertising by Leech (1966) used to identify advertising standards in print media advertising. The results of this study indicate that the elements of verbal and visual signs have collaboration and mutual support in each ad so that it has a message to persuade and make the reader interested (Pertiwi, 2016). 
This undergraduate thesis entitled "Semiotic Study on Visual and Verbal Signs of Taylor Swift's Music Video You Belong With Me 'and Its Song Lyrics "aims to identify the elements of visual signs displayed in the music video and analyze the meaning of the verbal signs contained in song lyrics from the music video. This paper uses two main theories, namely visual communication theory proposed by Dyer (1993) to identify elements of visual signs. The second theory is the theory of meaning by Leech (1983) used to analyze the types of meanings of verbal signs. The results of this study indicate that the elements of visual signs include several categories such as age, sex, hair, body, size, clothing, appearance, expression, eye contact, posture, touch, body movements, props, places found in all models except communication positions are only found on the main model (Darmayanti, 2016).

In the music video clips, the element of verbal signs is usually found when we watch it. But sometimes it is depending on the spectators. They usually do not understand the message or the meaning of the music video clip that they have watched.

Analyzing music video clip is interesting because in a music video clip we can analyze the message that the songwriter wants to deliver to us, especially in The Script music video clip entitled "The Millionaires". It is not just the lyrics, the movement of an actor or an actress but also reveals more various meaning through the expression in the music video clip. There are two problems discussed in this study:

1. What kinds of visual and verbal communication elements are used in the music video clip entitled Millionaires?

2. What messages are conveyed in the song lyrics?

\section{MATERIAL AND METHODS}

Research method can be defined as a careful study of a subject, especially to discover new facts or information about the subject.

The data was taken from a music video from a pop-rock band namely 'The Script'. The video clips chosen are determined in the terms of the song contents. The title is "Millionaires". "Millionaires" was released on 7 September 2012 as the fourth single from the pop-rock band The Script's record in \#3 as the third studio album released. The Script is an Irish rock band that consists of lead vocalist and keyboardist Daniel O'Donoghue, lead guitarist Mark Sheehan, and drummer Glen Power.

The song already received decent airplay before it was released and the music video for the single itself was released on $12^{\text {th }}$ June 2013.The filming for its music video, directed by Paul Banks and produced by James Young. Filming for the video takes in several locations, including shots overlooking Southmere Lake and in the playground at Abbey Wood Park in South East London. Most of the footage features a group of friends who out to the pub to just hang out. "Millionaires" was chosen as the data source because it has a valuable message that should be informed to the viewers, so everyone can apply the values and it contains a lot of visual and verbal signs. There are some messages from the music video clip that is the songwriter wants to deliver to the audience.

In collecting the data, the library research method was applied. It was used to get the information related to verbal communication elements and also to find out the meaning of The Script's music video clip. The techniques applied for this study were collected the music video clip from Youtube and got the original lyric from the album, watched the music video clip carefully, note-taking the lyrics of the music video, and listening thoroughly to the video clip. 
In the method of presenting data, the descriptive method was applied. The method was chosen because it was very suitable for the analysis. Descriptive means that the data presented by explaining it in words or sentence descriptively. The result of the analysis in this study was described in the form of a description to make a clear explanation. The technique of presenting data was by elaborating the visual and verbal communication elements found in the Millionaires Music video clip.

\section{FINDING AND DISCUSSION}

There are five components of visual communication elements that are used in this video clip. They are appearance, manner, activity, props, and setting, visual or images.

\section{Appearance}

There are five elements of appearance that are used in this music video clip; they are gender, nationality, hair, body, and looks. The observation of these elements will be explained as follows:

\section{a. Gender}

The classification of the gender in this video can be classified into female and male. Specifically, there were 18 persons involved in the clips

\section{b. Nationality and Race}

The script is known as the pop-rock of trio group band which has Irish members as their origin. The actors and actresses can be classified into white skin, dark brown skin, black skin, blue eyes, brown eyes, straight hair, curly hair, blonde hair, high and big shape. And from the video clip classification of nationality and race, it can be described that all persons involved in the clips are Ireland and England.

\section{c. Hairstyle}

Spike, straight, wavy, blonde, bald, short, and double ponytail are the hair's category of the band members and the actor/actress, which can be identified in this video

\section{d. Body Shape}

The bodies in this video present the characteristic of each character in the story. The description can be described as follows: The vocalist (Medium, tall), The guitarist (Medium, tall), The drummer (Medium, tall)

\section{e. Looks}

The looks of each character in this video are identified. The result can be described as follows:

The vocalist of The Script band is identified as a person who wears a black long sleeve coat with a black t-shirt inside, black long pants, grey sneaker shoes, and also a used necklace.

\section{Manner}

Manner indicates the behavior of emotion at any one time and it is manifested in the three main codes of non-verbal communication. Three elements of manner are expression, pose, and clothes.

a. Expression

In this video clip, the expression can be seen from the characters, which represent all the actor/actresses. The expression of the character, which occurs in this clip is a positive and negative expression like contented, purposeful, happy, delighted, gleeful expression also upset and angry expression.

\section{b. Pose}

Pose in this video clip can be a static or active pose because the pose which is seen in this video clip all the actors/ actress looks so enjoy and happy which involve the body movement. In the middle of the music video, the actor/ actress still keep any movement with walking, dancing, playing, sitting, drinking, standing, kissing until the end of the music video clip.

c. Clothes 
These are important carriers of the meaning which need to represent. They can range from the formal to the informal and can be smart, sophisticated, glamorous, elegant, trendy, or comfortable also casual. The clothes used in this video clip are variable. Jeans, $t$-shirt, short pant, are the example of non-formal clothes but comfortable. Dress, shirt, coat are the example of formal clothes that seen in this video by the actor/ actress.

\section{Activity}

Body gestures, movement, and posture can be related to what the actor is doing. There are seven kinds of body movement that can be identified in this video. They will be observed as follows:

Body Movement

Seven kinds of body movements can be identified in this video. They are:

a. Walking: This movement shown in almost all of the scenes in the video clip like when the couple with vest jeans and the red hair girl tried to warm each other at the beginning of the video and the end of the video when they were going back home together in the car park.

b. Dancing: In the middle of the video clip, the movement seems to be happy and full of joy, they were dancing and enjoyed the music inside the bar.

c. Playing: The body movement is shown in the middle of the video clip like when they enjoyed the fireworks together beside the river.

d. Sitting: This movement appears at beginning of the video when they were talking and laughing together under the pass and in the middle of the video clip when they have enjoyed the music in the bar.

e. Drinking: This movement can be seen clearly in the middle of the clip when the actor/actress in the bar drink to enjoyed themselves and the couple with vest jeans and the red hair girl in the restaurant celebrated.

f. Standing: This body movement appears in the middle of the video when they were standing beside the river enjoy watching the fireworks

g. Kissing: This movement is shown at the beginning and the middle of the scene when the couple between the man with vest jeans and the red hair girl were falling in love with each other

\section{Props and Setting}

The props for this video clip functioned to support the "The Millionaires" demonstration and other signifiers that relating the "The Millionaires" video clip. Many properties are used in this video clip. The main properties that used in this video clip were the music tools, drinking bottle, car, fireworks and flowers are the props that are used in this video. The mini-market, bar, and restaurant are also used as props in this video. The setting in this video consists of outdoor and indoor setting to support the video such as street in the video, under the road, the playground, the field beside the river until the car park are outdoor setting. And the bar, mini market, and restaurant are outdoor settings.

\section{Visual or Image}

The observation of analyzing photographs or images can be described as follows:

\section{a. Focus and Dept Vision}

The face of the actor/actress in every scene is observed from focus and depth vision. The face of the actor/actress is presented in the fuzzy description because the music video clip does not have a plot used there. There is positive and negative expression contained in the video.

\section{b. Close-ups}

The close-up technique can be seen on the whole of the clip. Most video clips used full 
and medium shoot to record the actor/actress's expression. The close-up picture can be seen the actor/actress appeared in most of the video.

\section{c. Camera Angle}

Four angles are used to produce the camera angle in this video clip, they are:

1. Front Angle

This angle is used to take pictures of the actor/actress in the clip that can be seen on most of the video to observe their expression.

2. Back Angle

The back angle is used in creating a picture of the actor/actress that can be seen in the beginning and the end of the clip when the guys sit together under the road and they're going back through the car park in the video.

\section{Above Angle}

The picture on the video clip taken by the camera from the above angle is the picture of the couple with vest jeans and the red hair girl walk through the small road beside a big building in the middle of the clip.

4. Side Angle

This angle used to take the picture that can be seen when the fat boy with a black polo t-shirt in the market, a big man with a white shirt and bald man whit black t-shirt in the bar, blonde women with a black jacket in the bar, the mature man with a grey suit and the mature woman with glasses in the bar, the boys playing football, the couple with vest jeans and red hair girl in the restaurant.

\section{The Verbal \& Visual Communication used in "Millionaires" Video Clip}

The verbal and visual representation for the "Millionaires" song can be seen in the following analysis.

\section{Verbal Communication}

They're kicking us out sayin' it's time to close We're leaning on each other tryin' to beat the cold

I carry your shoes and I gave you my coat, yeah of

\section{Visual Communication}

As the beginning of the music video starts, the two actors The boy with vest jeans and The girl with red hair walk with very straight expressions to represent problems that they are facing. The problems are very abstract but the title of the song itself, Millionaires mean money problems. The lyric says 'I gave you my coat' depicts exactly what is shown in the video when the boy with vest jeans tries to cover the girl. The girl has worn her jacket, while the boy wears a vest with no sleeve but he is still willing to give warmth as the interpretation of the coat in the lyric.

\section{CONCLUSION}

This study has discussed the visual and verbal communication used in the music video clip. It is focused on the discussion of visual and verbal communication elements used in the music video. Besides that, this study also focused on the analysis of the song messages related to the visual sign representation in the music video clip entitled "The Millionaires". Based on the analysis and discussion, the following points can be presented as a conclusion.

From the analysis, the visual communication elements found are 13 elements from 5 components of visual elements, they are appearance, manner, activity, props, and setting, visual or images. In the appearance category, 5 elements were found, those elements are gender, nationality, hair, body, and looks. In the manner component, 3 elements were found, they are expression, pose, and clothes. In the activity component, only 1 element was found, it was body movement. In the props and setting component, it was found consisted in the outdoor and indoor setting to support the video. In the Visual or Image component, it was found 3 elements, those are focus and depth vision, close-ups, and camera angle. 
There are some meanings used in supporting verbal communication in the "Millionaires". The music video clip used 4 types of meanings, those are conceptual meaning, connotative meaning, affective meaning, and thematic meaning in the analysis of the lyrics.

\section{REFERENCES}

[1] Brent. 2009. The Journal of Semiotic Society of America. Available from: www.google.com

[2] Chandler, Daniel. 2002. Semiotics: the Basics. UK Routledge.

[3] Halliday, M.A.K. 1985. Language, context, and text: aspects of language in a social-semiotic perspective. Oxford: Oxford University Press

[4] The Script. 2012. \#3 Album: The Millionaires. United States of America

[5] Chandler, Daniel. 2001. Semiotic for Beginners. Aberystwyth: Aberystwyth University Press.

[6] Goodwin, Andrew. 1992. Dancing in the Distraction Factory: Music Television and Popular Culture. Minneapolis, Minnesota: University of Minnesota

[7] Lester, Paul Martin. 2002. Visual Communication: Images With Messages Visual Illustration. Fullerton: California State University

[8] Dyer, Gillian. 1993. Advertising As Communication. London and New York: Routledge.

[9] Halliday, M.A.K. 1990. Spoken and written language, 2. ed, 2. impr. ed, Language education. Oxford Univ. Press, Oxford.

[10] Leech, G. 1974. Semantics: The Study of Meaning. A Penguin book Language, linguistics. Penguin Books, Harmondsworth

[11] The Script. 2013. Millionaires Music Video. Available from: URL: http:www.youtube.com/

[12] Kurniawan, I Wayan. 2011. Verbal and Visual Message Reflected On Music Video of Green Day. Denpasar: English Department, Faculty of Letters, Udayana University.

[13] Pidada, 2012. Verbal and Visual Message of Barrack Obama Political Cartoons. Denpasar: English Department, Faculty of Letters, Udayana University.

[14] Suliani, Kadek. 2012. Verbal and Visual Communication Elements in the Celine Dion's Vide006F Clips. Denpasar: English Department, Faculty of Letters, Udayana University.

[15] Adi, I Putu. 2016. The Analysis Of Verbal And Visual Sign Of Adidas. Humanis Journal of Arts and music video clip entitled

Humanities. Advertisement. Vol 17.1 Oktober 2016: 104 $-111$

[16] Arriawan, 2014. Verbal and Visual Messages In English Printed Car Advertisement. Humanis Journal of Arts and Humanities. Volume 8. No. 3. September 2014

[17] Asti, Ni Putu. 2014. Analysis Of Product Advertisements On Magazines With Verbal And Visual Signs. Humanis Journal of Arts and Humanities. Volume 7. No. 3. Juni 2014

[18] Ayu, Dewa. 2016. Visual And Verbal Communication In Michael Jackson's Video Clip Entitled "Black Or White". Humanis Journal of Arts and Humanities. Vol 17.2 Nopember 2016: 28 -35

[19] Ayu, Putu. 2017. Analysis of Verbal and Visual Aspects in Taylor Swift's Music Video Out of the Woods. Humanis Journal of Arts and Humanities. Vol 19.1 Mei 2017:132-140

[20] Bagus, I Gusti. 2015. Verbal And Visual Signs Of Nike Advertisement: A Semiotics Analysis. Humanis Journal of Arts and Humanities. Volume 13. No.2. Nopember 2015

[21] Darmayanti, 2016. "Semiotic Study on Visual and Verbal Signs of Taylor Swift's Music Video" You Belong With $\mathrm{Me}$ "And Its Song Lyrics. Humanis Journal of Arts and Humanities. Vol 17.1 Oktober 2016: 175 - 183

[22] Fridayanti, 2018. Verbal and Visual Communication in the Movie The Hunger Games. Humanis Journal of Arts and Humanities. Vol 22.4 Agustus 2018: 604-611

[23] Pertiwi, 2016. The Analysis of Verbal and Visual Signs in Female Cosmetics Advertisement. Humanis Journal of Arts and Humanities. Vol 17.2 Nopember 2016: 248 253

[24] Prawiranatha, 2018. Verbal and Visual Signs of Advertisement in National Geographic Traveller Magazine. Humanis Journal of Arts and Humanities. Vol 22.4 Nopember 2018: 1028-1032

[25] Sriumiyanti, 2014. Verbal and Visual Sign In Doushite Kimi Wo Suki Ni Natte Shimattan Darou And Stand By U. Humanis Journal of Arts and Humanities. Volume 7. No. 1. April 2014

[26] Suarmita, 2016. Connotative Meaning Of Verbal And Visual Signs In Printed Perfume Advertisements. Humanis Journal of Arts and Humanities. Vol 17.3 December 2016: 73 - 80 